\title{
Effects of Exercise on Cognitive Function in Older People with Dementia: A Randomized Controlled Trial
}

\author{
Annika Toots ${ }^{\mathrm{a}, \mathrm{b}, *}$, Håkan Littbrand $^{\mathrm{a}, \mathrm{b}}$, Gustaf Boström $^{\mathrm{b}}$, Carl Hörnsten $^{\mathrm{b}}$, Henrik Holmberg ${ }^{\mathrm{c}}$, \\ Lillemor Lundin-Olsson ${ }^{\mathrm{a}}$, Nina Lindelöf ${ }^{\mathrm{a}, \mathrm{b}}$, Peter Nordström ${ }^{\mathrm{b}}$, Yngve Gustafson ${ }^{\mathrm{b}}$ \\ and Erik Rosendahl ${ }^{\mathrm{a}, \mathrm{b}}$ \\ ${ }^{a}$ Department of Community Medicine and Rehabilitation, Physiotherapy, Umeå University, Umeå, Sweden \\ ${ }^{\mathrm{b}}$ Department of Community Medicine and Rehabilitation, Geriatric Medicine, Umeå University, Umeå, Sweden \\ ${ }^{\mathrm{c}}$ Department of Public Health and Clinical Medicine, Umeå University, Umeå, Sweden
}

Accepted 30 June 2017

\begin{abstract}
.
Background: Although physical exercise has been suggested to influence cognitive function, previous exercise studies show inconsistent results in people with dementia.

Objectives: To investigate effects of exercise on cognitive function in people with dementia.

Method: The Umeå Dementia and Exercise (UMDEX) study, a cluster-randomized controlled trial, was set in 16 nursing homes in Umeå, Sweden. One hundred-and-forty-one women and 45 men with dementia; mean age of 85 y and mean MiniMental State Examination (MMSE) score of 15, were randomized to a High-Intensity Functional Exercise program or a seated attention control activity. Blinded assessors measured global cognitive function using the MMSE and the Alzheimer's disease Assessment Scale - Cognitive subscale (ADAS-Cog), and executive function using Verbal fluency (VF) at baseline and 4 months (directly after intervention completion), and MMSE and VF at 7 months.

Results: Linear mixed models showed no between-group effects in mean difference from baseline (95\% confidence intervals, $\mathrm{CI})$ at 4 months in MMSE $(-0.27 ; 95 \% \mathrm{CI}-1.4$ to $0.87, p=0.644)$, ADAS-Cog $(-1.04,95 \% \mathrm{CI}-4$ to $1.92, p=0.491)$, or VF $(-0.53,95 \% \mathrm{CI}-1.42$ to $0.35, p=0.241)$ or at 7 months in MMSE $(-1.15,95 \% \mathrm{CI}-2.32$ to $0.03, p=0.056)$ or $\mathrm{VF}(-0.18$, $95 \% \mathrm{CI}-1.09$ to $0.74, p=0.707)$.

Conclusion: A 4-month, high-intensity functional exercise program had no superior effects on global cognition or executive function in people with dementia living in nursing homes when compared with an attention control activity.
\end{abstract}

Keywords: Cognition, dementia, exercise, residential facilities

\section{INTRODUCTION}

Dementia is a leading cause of disability and dependence in older people worldwide [1]. Features of dementia include a progressive decline in cognition, including deficits to memory as well as

\footnotetext{
*Correspondence to: Annika Toots, Department of Community Medicine and Rehabilitation, Physiotherapy, Umeå University, S-901 87 Umeå, Sweden. Tel.: +46 90 7866329; E-mail: annika. toots@umu.se.
}

language or executive function, and a subsequent loss of social or occupational function, including activities of daily living (ADL) [2]. Furthermore, dementia is frequently accompanied by deficits to balance and gait [3], which appear especially affected in certain types of dementia such as vascular dementia, dementia with Lewy bodies, or Parkinson's disease dementia compared with Alzheimer's disease (AD) [4]. Gait and balance dysfunction have been linked to cognitive function, in particular executive function [5]. Beside 
cognitive impairment, gait and balance deficits are associated with dependence in ADLs. Pharmacological treatment has been shown to benefit cognitive function and dependence in ADLs in people with AD [6], but side effects are common and the usefulness in people with vascular dementia remains less certain [7]. Further evaluation of complimentary disease modifying treatment to optimize cognitive function and preserve independence in people with dementia is imperative, given the considerable burden of dementia for the individual, their family, and society.

About a third of all AD cases may be attributed to potentially modifiable risk factors, predominantly physical inactivity [8], which implies that the disease can be prevented. Various potential mechanisms have been explored. Human and animal studies suggest that physical exercise can stimulate improvement in cerebrovascular function, perfusion, and neuroplasticity in the brain, which may prevent the progressive loss of cognitive function associated with aging and disorders such as dementia [9, 10]. However, causal effects of physical exercise on cognitive function remain equivocal in older people [11, 12]. Furthermore, although promising evidence suggests that exercise affects dependence in ADLs in people with dementia [13, 14], randomized controlled trials investigating effects of exercise on cognition show inconsistent results [13, 15-19]. Positive exercise effects on cognitive function seem apparent only in studies that are small or lack blinded testers [17-21] or comparable attention control groups [17-22]. To explore the effects of exercise as a single intervention in people with dementia, the additional attention brought by the intervention may need to be matched in the control group because amount of attention has been shown to influence cognitive function in this population [23], which is often characterized by limited social interaction $[24,25]$. In addition, no study has compared the effects of exercise between dementia types.

The aim of this study was to investigate effects of a high-intensity functional exercise program on cognitive function in people with dementia who had mild to severe cognitive impairment, and whether the effects were moderated by cognitive level at baseline, sex, or type of dementia.

\section{MATERIAL AND METHODS}

This study was part of the Umeå Dementia and Exercise Study (UMDEX), a cluster-randomized controlled trial conducted in Umeå, Sweden, and has been described in detail elsewhere [14, 26, 27]. The study was set in 16 nursing homes, which comprised general and dementia specialized units, all with private rooms and staff on hand, as well as units with private apartments with access to on-site nursing and care staff. The study protocol (ISRCTN31767087) is published on the ISRCTN registry.

\section{Participants}

Enrollment and baseline testing were performed in August through September 2011. Criteria for inclusion were a Mini-Mental State Examination (MMSE) score $\geq 10$ [28], a dementia diagnosis [2], age $\geq 65 \mathrm{y}$, dependent on assistance in $\geq 1$ personal activity of daily living according to the Katz Index [29], ability to stand up from a chair with armrests with assistance from $\leq 1$ person, physician's approval, and ability to hear and understand spoken Swedish sufficiently to participate in assessments. All individuals included in the study gave informed oral consent to participation, which was confirmed by their next of kin. A total of 864 nursing home residents were screened. Age $(p=0.189)$ and MMSE score $(p=0.713)$ did not differ between participants included and those who declined participation ( $n=55$; Fig. 1). A larger proportion of men than women declined participation (34\% versus $18 \% ; p=0.008$ ). Baseline characteristics of the 186 participants are presented in Table 1.

\section{Randomization}

Participants were randomized after completion of enrollment process and baseline assessment to ensure concealed allocation. Clusters $(n=36)$ of three to eight participants each (that lived in the same wing, unit, or floor) were formed. The randomization was stratified in all nursing homes except one, which only had a single cluster; an approach that aimed to have participants in both groups in each of the nursing homes and reduced the risk of factors associated with site to influence the outcome. Two researchers not involved in the study performed randomization by drawing lots using sealed opaque envelopes. The Regional Ethics Review Board in Umeå approved the study (2011-205-31M).

\section{Intervention}

The exercise and attention control activities were conducted at the nursing homes in small groups 


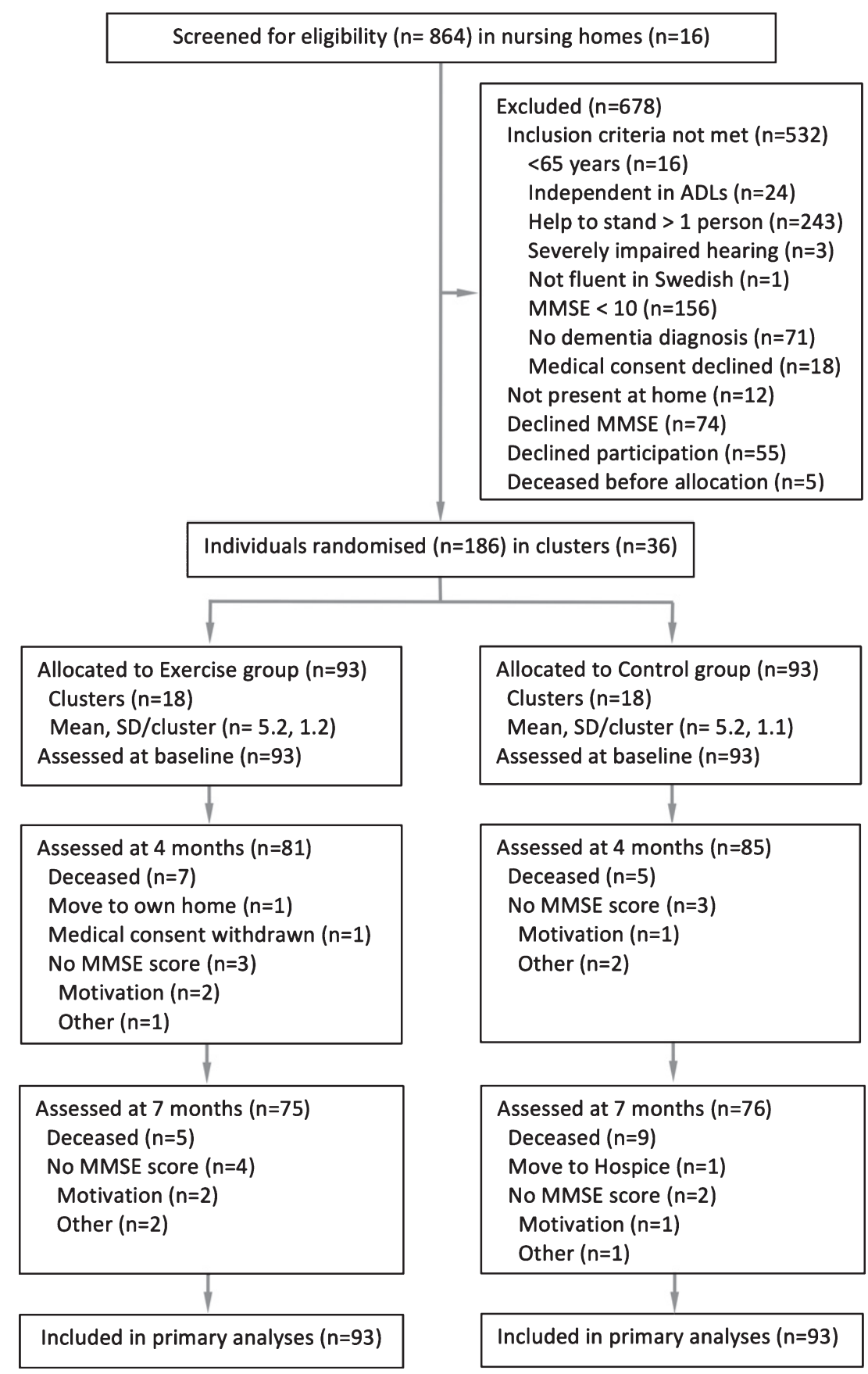

Fig. 1. Flow of participants through the study. ADLs, Activities of Daily Living; MMSE, Mini-Mental State Examination.

( $n=3-8)$, each supervised by two Physical Therapists (PT) and one Occupational Therapist (OT) or OT assistant. The intervention started October 2011 and lasted four months (40 sessions in total) and consisted of five 45-minute sessions per two-week period. When possible, supervised individual sessions were offered when participants were unable to attend a group session. While no activities were provided after the 4-month intervention, participation in activities other than provided by the study was not restricted at any time.

The exercise intervention was based on the HighIntensity Functional Exercise (HIFE) program, which includes a model for exercise selection and a 
Table 1

Baseline characteristics

\begin{tabular}{|c|c|c|c|}
\hline Characteristic & $\begin{array}{l}\text { Total } \\
n=186\end{array}$ & $\begin{array}{c}\text { Exercise } \\
n=93\end{array}$ & $\begin{array}{c}\text { Control } \\
n=93\end{array}$ \\
\hline Age & $85.1(7.1)$ & $84.4(6.2)$ & $85.9(7.8)$ \\
\hline Female, $n(\%)$ & $141(75.8)$ & $70(75.3)$ & $71(76.3)$ \\
\hline \multicolumn{4}{|l|}{ Dementia type, $n(\%)$} \\
\hline Vascular dementia & 77 (41.4) & $36(38.7)$ & $41(44.1)$ \\
\hline Alzheimer's disease & $67(36.0)$ & $34(36.6)$ & $33(35.5)$ \\
\hline Other & $27(14.5)$ & $15(16.1)$ & $12(12.9)$ \\
\hline Mixed Alzheimer's disease/Vascular dementia & $15(8.1)$ & $8(8.6)$ & $7(7.5)$ \\
\hline \multicolumn{4}{|l|}{ Diagnoses and medical conditions, $n(\%)$} \\
\hline Depressive disorders & $107(57.5)$ & $53(57.0)$ & $54(58.1)$ \\
\hline Delirium previous week & $102(54.8)$ & $48(51.6)$ & $54(58.1)$ \\
\hline Previous Stroke & $57(30.6)$ & $33(35.5)$ & $24(25.8)$ \\
\hline Heart failure & $56(30.1)$ & $24(25.8)$ & $32(34.4)$ \\
\hline Previous hip fracture & $53(28.5)$ & $28(30.1)$ & $25(26.9)$ \\
\hline Angina pectoris & $49(26.3)$ & $21(22.6)$ & $28(30.1)$ \\
\hline Diabetes mellitus & $29(15.6)$ & $18(19.4)$ & $11(11.8)$ \\
\hline \multicolumn{4}{|l|}{ Prescription medication, $n(\%)$} \\
\hline Analgesics & $112(60.2)$ & $55(59.1)$ & $57(61.3)$ \\
\hline Antidepressants & $102(54.8)$ & $58(62.4)$ & $44(47.3)$ \\
\hline Diuretics & $88(47.3)$ & $41(44.1)$ & $47(50.5)$ \\
\hline Vitamin D-Calcium supplement & $60(32.3)$ & $32(34.4)$ & $28(30.1)$ \\
\hline Cholinesterase inhibitor & $40(21.5)$ & $25(26.9)$ & $15(16.1)$ \\
\hline Benzodiazepines & $40(21.5)$ & $19(20.4)$ & $21(22.6)$ \\
\hline Neuroleptics & $31(16.7)$ & $11(11.8)$ & $20(21.5)$ \\
\hline Memantine & $12(6.5)$ & $7(7.5)$ & $5(5.4)$ \\
\hline Number of drugs, mean (SD) & $8.3(3.8)$ & $8.4(4.0)$ & $8.2(3.7)$ \\
\hline \multicolumn{4}{|l|}{ Assessments } \\
\hline Mobility Device, $n(\%)$ & $145(78.0)$ & $76(81.7)$ & $69(74.2)$ \\
\hline Mini Nutritional Assessment $(0-30), n=185^{\mathrm{a}}$ & $21.1(2.7)$ & $21.3(2.8)$ & $20.9(2.6)$ \\
\hline Geriatric Depression Scale-15 (0-15), $n=183^{\mathrm{b}, \mathrm{c}}$ & $3.8(3.2)$ & $4.0(3.4)$ & $3.6(2.9)$ \\
\hline Neuropsychiatric Inventory $(0-144)^{\mathrm{b}}$ & $14.8(14.2)$ & $15.2(15.8)$ & $14.4(12.6)$ \\
\hline Vision impairment, $n(\%)^{\mathrm{d}}$ & $26(14.0)$ & $10(10.8)$ & $16(17.2)$ \\
\hline Hearing impairment, $n(\%)^{\mathrm{e}}$ & $52(28.0)$ & $20(21.5)$ & $32(34.4)$ \\
\hline $\begin{array}{l}\text { Self-reported health; good, very good, or excellent, } \\
n(\%)\end{array}$ & $119(64.0)$ & $60(64.5)$ & $59(63.4)$ \\
\hline Barthel ADL Index $(0-20)^{\mathrm{a}}$ & $10.9(4.4)$ & $10.7(4.5)$ & $11.0(4.4)$ \\
\hline Berg Balance Scale $(0-56)^{\mathrm{a}}$ & $28.9(14.5)$ & $28.6(14.3)$ & $29.3(14.7)$ \\
\hline \multicolumn{4}{|l|}{ Outcome measures } \\
\hline Mini-Mental State Examination $(0-30)^{\mathrm{a}}$ & $14.9(3.5)$ & $15.4(3.4)$ & $14.4(3.5)$ \\
\hline $\begin{array}{l}\text { Alzheimer's disease assessment scale - Cognitive } \\
\text { section }(0-70), n=183^{\mathrm{b}}\end{array}$ & $31.6(10.8)$ & $31.8(11.4)$ & $31.3(10.3)$ \\
\hline Verbal fluency, $n=182^{\mathrm{a}}$ & $6.4(3.8)$ & $6.8(4.1)$ & $5.9(3.5)$ \\
\hline
\end{tabular}

Values are mean (SD) unless stated otherwise. Numbers reported after covariates indicate number of measurements available when values were missing. ${ }^{a}$ Higher scores indicate better status. ${ }^{b}$ Lower scores indicate better status. ${ }^{c}$ When at least 10 Geriatric Depression Scale (GDS-15) questions were answered, missing data were imputed using the mean score of questions answered. ${ }^{\mathrm{d}}$ Unable to read words printed in 5-mm capital letters, with or without glasses, at a normal reading distance. ${ }^{\mathrm{e}}$ Using hearing aid and/or unable to hear a conversation held at usual speaking voice from a distance of 1 meter. SD, standard deviation.

definition of exercise intensity, and is available from authors and described in detail elsewhere [14, 30, 31]. The HIFE program comprises 39 functional exercises that aim to improve lower limb strength, balance, and mobility. Exercises are performed in weightbearing positions, e.g., rising from a chair, stepping, and walking, and selected depending on individual degree of functional deficit. The intensity in muscle strengthening exercises was defined relative to repetition maximum $(\mathrm{RM})$ [32], i.e., "the maximal number of times a load can be lifted before fatigue using good form and technique" [33]. The supervising PTs estimated RM in each exercise set, based on observation of participant response and performance. High exercise intensity was aimed for and defined as $8-12 \mathrm{RM}$, thus progressed when able to exceed 12 repetitions [30, 31]. Strength exercises were progressed by adjustment of load, for example, by altering the step or seat height, or by adding weights to a weighted waist belt (maximum $12 \mathrm{~kg}$ ). 
High-intensity balance exercises aimed to fully challenge postural stability, i.e., performed at or near the limit of maintaining an upright position [30,31], and were progressed by, for example, narrowing the base of support or changing the support surface. Exercises were adapted throughout the intervention to meet participants' symptoms and changes in health and functional status. Participants were supervised individually to promote the highest possible exercise intensity. For safety, participants wore belts with handles so that PTs could provide support if needed when postural stability was fully challenged, thereby preventing falls. Unnecessary support was avoided. Participants were encouraged to exercise at moderate strength intensity (13-15RM) the first two weeks. At the end of each session leaders completed a structured protocol for each participant pertaining to adverse events and intensity achieved in muscle strength and balance exercises, which was estimated separately as high, moderate, or low according to the pre-defined scale [31].

The attention control group participated in structured activities that were developed by the OTs and OT assistant that led the activities. The activities were structured around topics believed to be interesting for older people, including local wild life, seasons, and holidays. While seated in a group, participants conversed, sang, listened to music or readings, and/or looked at pictures and objects.

\section{Outcome measures}

Trained research staff (PTs and physicians) performed all measurements. Baseline measurements were followed up on intervention completion at four months, and also at seven months to examine effects in the longer term. Testers were blinded to activity allocation and previous test results. The blinding was preserved throughout all cognitive tests by a predefined strategy to change tester if allocation was revealed. Global cognition was measured using the MMSE $[28,34]$ and the Alzheimer's Disease Assessment Scale-Cognitive Subscale (ADAS-Cog) [35], which have both been shown to have high test-retest reliability and be sensitive to change in people with mild to moderate dementia [28, 34-36], thus applicable to the present study's sample population. The ADAS-Cog was measured at baseline and at four months only. The MMSE (0-30) is an established measure of cognitive function, comprising 20 questions related to domains, e.g., attention, language, word recall, orientation to time and place, and where a higher score indicate better function. The ADAS-Cog $(0-70)$ is measure of cognitive function widely used as an outcome measure in pharmaceutical trials targeting slowing progression of Alzheimer's disease, and was designed to improve assessment of subtle changes in symptoms [36]. Similar to the MMSE, the ADAS-Cog measures various domains, but in contrast to the MMSE, a higher score indicates worse cognitive function. A minimal or maximal score was given on items on the MMSE or ADAS-Cog respectively when participants refused to answer, or when prevented by vision, hearing, or motor impairments.

Verbal fluency (VF) was used to measure executive function, and has been shown to have substantial testretest reliability and be sensitive to change in people with dementia [37]. Participants were asked to name as many animals as possible within one minute, and a higher number of animals named indicated better executive function. The rationale for choosing the VF test was its simple design, which is an advantage in populations that include participants with severe cognitive impairment to avoid missing values.

\section{Descriptive measurements}

Nutritional status was assessed using the Mini Nutritional Assessment (0-30) [38]. Vision was considered impaired when unable to read a word printed in five-mm capital letters, with or without glasses, at normal reading distance. Self-reported health was evaluated using the first question from the Short-Form-36 Health Survey [39]. Symptoms of depression were assessed using the 15-item Geriatric Depression Scale (0-15) [40]; when $\geq 10$ questions were answered, missing data was imputed using the individual mean of questions answered. Electronic records of past medical history, which included brain imaging in most cases, current pharmaceutical treatment, and assessment results, were used to record dementia type, depressive disorders, and delirium diagnoses. A specialist in geriatric medicine reviewed and confirmed these diagnoses according to DSM-IVTR criteria [2].

\section{Data analysis}

Sample size was calculated for the main outcome in the UMDEX study, the Barthel ADL Index [14]. A sample size of 183 participants was required to verify significant intervention effects at a statistical power of $80 \%$ at the 4-month follow-up, a significance level of 0.05 , two-sided, and a presumed dropout rate of $10 \%$. 
Baseline characteristics are presented as means (standard deviation) or frequencies (percentages). A comparison between exercise and attention control groups was performed using Student $t$-test or Pearson chi-squared test, and associations $(r \geq 0.3)$ with changes in outcome measures at 4 and 7 months using Pearson correlation coefficient. While antidepressant use differed between groups $(p=0.04)$ and was adjusted for in analyses, no other variables differed between groups at baseline. No variable was found to associate with change in outcome measures above predefined levels.

In an intention-to-treat approach all available data for participants were analyzed according to original allocation and regardless of level of attendance. Linear mixed effects models were used to analyze longitudinal changes in MMSE and VF from baseline to 4 and 7 months, and in ADAS-Cog from baseline to 4 months, using interaction terms for activity and time point and adjustment for age, sex, and antidepressant use as fixed effects, and individual and cluster allocation as random effects. Baseline values for outcome measures were included in the dependent variable to avoid loss of data. The least square mean within-group difference was estimated from these models.

Subgroup analyses were conducted according to dementia type and cognitive level by adding interaction terms to adjusted models. Dementia type was dichotomized into AD versus all other (nonAlzheimer's, non-AD) types of dementias [14], in part to aid comparison of results with studies that include participants with $\mathrm{AD}$ only, and also since previous studies indicate that relevant differences between these two dementia subgroups may exist [3,14]. Level of cognitive impairment was dichotomized based on the median MMSE score of 15, ADAS-Cog score of 30, and VF score of 6.

The influence of outliers was explored in sensitivity analyses by repeating adjusted analyses after removal of extreme values. The influence of level of adherence on exercise effects was explored by adding an interaction term. Level of adherence was dichotomized based on the median number of activity sessions attended, which was 32 of the 40 possible, and which also correlates with the twice weekly recommended dose of strength exercise in older people [41, 42].

All analyses were performed using IBM SPSS statistics for Macintosh version 23.0 (IBM Corp. Armonk, NY) and R version 3.2.2 (R Core Team, Vienna, Austria) software. All statistical tests were two tailed and $p<0.05$ was considered to be statistically significant.

\section{RESULTS}

In total, 141 women and 45 men, with mean \pm standard deviation (SD) age of $85.1 \pm 7.1 \mathrm{y}$ and a MMSE score of $14.9 \pm 3.5$ were included (Table 1). Sixty-seven (36.0\%) of participants had $\mathrm{AD}, 77$ (41.4\%) vascular dementia, and $15(8.1 \%)$ mixed $\mathrm{AD}$ and vascular dementia. Twenty-seven $(8.1 \%)$ participants had other types of dementia including $4(2.2 \%)$ alcohol related, $1(0.5 \%)$ dementia with Lewy bodies, 4 (2.2\%) frontotemporal, 2 (1.1\%) Parkinson's disease dementia, 6 (3.1\%) mixed vascular and other types, and $10(5.4 \%)$ had unspecified dementia. Over the 4-month intervention period, adherence in the exercise group was $73 \%$ and in the attention control group 70\%. All adverse events recorded during exercise sessions were minor or temporary [14]. Strength exercises were estimated to be performed at moderate intensity $40 \%$ and at high intensity $45 \%$ of attended sessions, and balance exercises at moderate intensity $27 \%$ and high intensity $63 \%$ of attended sessions.

\section{Outcomes}

There were no differences in mean change from baseline between exercise and activity groups (95\% confidence intervals, $\mathrm{CI}$ ) at 4 months in MMSE $(-0.27 ; 95 \% \mathrm{CI}-1.4$ to $0.87, p=0.644)$, ADAS-Cog $(-1.04,95 \% \mathrm{CI}-4$ to $1.92, p=0.491)$, or VF $(-0.53$, $95 \% \mathrm{CI}-1.42$ to $0.35, p=0.241$ ) or 7 months in $\operatorname{MMSE}(-1.15,95 \% \mathrm{CI}-2.32$ to $0.03, p=0.056)$ or VF $(-0.18,95 \%$ CI -1.09 to $0.74, p=0.707$; Table 2 , Fig. 2).

In interaction analyses, exercise effects on MMSE, VF, or ADAS-Cog did not differ according to sex or dementia type (Supplementary Tables 1-2). In addition, the interaction analyses indicated that exercise effects on VF or ADAS-Cog did not differ according to cognitive level at baseline at any follow-up. While the exercise effects on MMSE did not differ according to cognitive level at the four-month follow-up, it differed at the seven-month follow, with a negative exercise effect in participants with lower cognitive function at baseline (Supplementary Table 3).

In sensitivity analyses, when adjusted analyses were repeated after removal of extreme outliers at the 4-month follow-up (ADAS-Cog = 4, VF = 1), the intervention effects on cognitive function remained 
Table 2

Within- and between-group differences from baseline in the Mini-mental state examination (MMSE), the Verbal fluency test (VF), and the Alzheimer's disease assessment scale - cognitive section (ADAS-Cog)

\begin{tabular}{|c|c|c|c|c|c|c|c|}
\hline \multirow[b]{2}{*}{ Measure } & \multicolumn{4}{|c|}{ Within-group differences } & \multicolumn{3}{|c|}{ Between-group differences } \\
\hline & $n$ & Exercise, Mean m/s (SE) & $n$ & Control, Mean m/s (SE) & Mean m/s (95\% CI) & $p$ & $\mathrm{ICC}^{\mathrm{a}}$ \\
\hline MMSE & & & & & & & 0.11 \\
\hline 4 months & 81 & $-1.15(0.41)$ & 85 & $-0.93(0.4)$ & $-0.27(-1.4$ to 0.87$)$ & 0.644 & \\
\hline 7 months & 75 & $-2.25(0.42)$ & 76 & $-1.11(0.42)$ & $-1.15(-2.32$ to 0.03$)$ & 0.056 & \\
\hline VF & & & & & & & 0.04 \\
\hline 4 months & 80 & $-0.74(0.32)$ & 81 & $-0.21(0.32)$ & $-0.53(-1.42$ to 0.35$)$ & 0.241 & \\
\hline 7 months & 74 & $-0.89(0.33)$ & 72 & $-0.71(0.33)$ & $-0.18(-1.09$ to 0.74$)$ & 0.707 & \\
\hline ADAS-Cog & & & & & & & 0.08 \\
\hline 4 months & 84 & $1.51(1.06)$ & 82 & $2.55(1.07)$ & -1.04 ( -4 to 1.92$)$ & 0.491 & \\
\hline
\end{tabular}

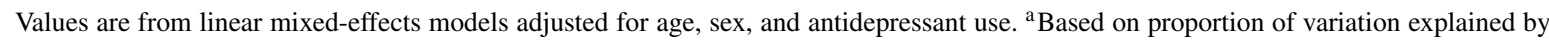
cluster. ICC, intracluster correlation coefficient; $n$, number of participants with complete data.

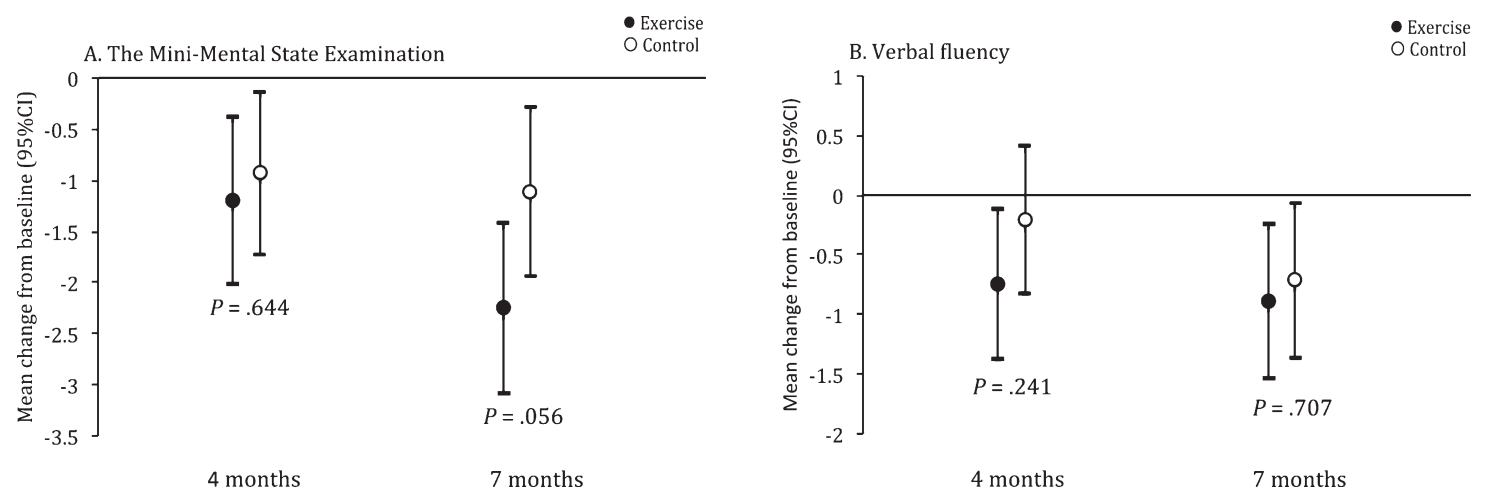

Fig. 2. Between-group differences from baseline in Mini-Mental State Examination (MMSE) and Verbal fluency (VF). Values are least square mean change from baseline, with 95\% confidence intervals, from linear mixed-effects models adjusted for age, sex, and antidepressant use.

essentially the same (data not shown). Exercise effects on MMSE, VF, and ADAS-Cog did not differ according to level of adherence (data not shown).

\section{DISCUSSION}

In this study of older people with dementia living in nursing homes, when compared with a control activity a 4-month, high-intensity functional exercise program did not result in significant differences in global cognitive or executive function. The exercise effects did not differ according to dementia type, sex, or cognitive level at baseline.

This result concurs with that of two large randomized controlled trials of people with dementia set in nursing homes and communities, respectively, and with multicomponent interventions (combinations of muscle strength, balance, walking, or other aerobic exercise) targeting functional improvement $[16,18]$. In the studies, no exercise effects on global cognitive function were observed, neither in comparison with low-intensity exercise [16] nor usual care [18]. Although effects on cognitive function are conceivable through strength exercise, the absence of effects in the present study may be attributed to a limited aerobic component in the exercise program, as cardiovascular improvement in particular has been proposed to mediate effects on cognitive function [10]. However, results of our study also agree with a large study of people with dementia in the community setting, where a four-month, moderateto-high-intensity, aerobic exercise program had no effects on global cognitive function when compared with usual care in intention-to-treat analyses [43], even though cardiorespiratory fitness was shown to improve [44].

While knowledge regarding optimal exercise intensity, frequency, and duration for effects on cognitive function is still inconclusive [9], participants may not have reached the minimal effective dose. Nevertheless, most participants exercised at a moderate-to-high intensity, and half attended at least twice per week, which is encouraging considering this population of older people with dementia living in nursing homes. Furthermore, for effects on cognitive function the duration of the exercise intervention 
may be critical, and the four-month intervention in our study was perhaps too short. Dependent on type of exercise and intensity, up to six to twelve-month interventions have been proposed for observable effects on brain structure [9], and indeed some longer trials in people with dementia show positive effects [18, $19,21]$ though inferences are limited by methodological constraints. Furthermore, the observation of structural changes in the brain may not necessarily equal corresponding effects on cognitive function [45], which may take even longer. In addition, it has been suggested that certain cognitive domains such as executive function may be particularly sensitive to effects of exercise [9]. In people at risk of cognitive decline, the longest and largest trial to date found that while a two-year multicomponent exercise program had no effects on global cognitive function, subgroup effects on executive function was evident [11]. However, the present study found no effects on either global or executive cognitive function, which perhaps was due to the shorter duration.

Our study indicated negative exercise effects on cognition that approached statistical significance in MMSE at the 7-month follow-up, particularly in participants with lower cognitive function at baseline. However, since 3 months had transpired since the end of the intervention, during which no activities were offered by the study, causal inferences are limited. Furthermore, the result was not substantiated in analyses on VF or ADAS-Cog in the present study.

We have previously reported beneficial effects of a high-intensity functional exercise program on balance and dependence ADLs in people with nonAlzheimer's type of dementia living in nursing homes [14]. These results together with the results from the present study concur with that of a systematic review in people with dementia, which indicate that while exercise seems to improve ability to perform ADLs, there was no clear evidence of benefits on cognitive function [13]. Despite the limited causal evidence that exercise affects cognitive function, the activity limitation in people with dementia may still be attenuated by physical exercise. Dependence in ADLs is influenced not only by cognitive function but also physical function. Exercise programs may improve gait and balance, and, therefore, dependence may also decline in ADLs [13]. For this purpose, a 4-month, high-intensity functional exercise program seems effective [14].

Strengths of this study include the randomized design, a non-exercise attention control group, blinded assessors, and a comparison between dementia types, all of which contribute to results that may be generalized to older people with dementia living in nursing homes. This study also has limitations. The ADAS-Cog was only tested at baseline and 4-month follow-up due to limited funding, which was unfortunate for comparison of effects between tests; however, all 3 cognitive tests indicated similar results at 4 months. Although baseline assessment of MMSE was conducted during the enrollment process, which was on average 1 month prior to the baseline assessments of ADAS-Cog and VF, the time difference did not differ between groups. Components of the attention control activity may resemble cognitive stimulation, i.e., engagement in activities that provide stimulation for thinking, concentration, and memory, with the aim to improve cognitive and social function [46]. The control activities in the present study did not aim to enhance cognitive function; however, a certain effect cannot be ruled out. While it would have been interesting to analyze exercise effects more closely based on dementia type, this was prevented by concerns regarding power. Although the etiology in the non-AD group varied, which may affect the implication of these results, $82 \%$ had a vascular type of dementia, either alone or in combination with other types of dementia. The sample size was comparatively large, yet based on power calculations on a different outcome; subgroup analyses may still have limited power and should be interpreted with caution.

\section{Conclusion}

A 4-month, high-intensity functional exercise program had no superior effects on global cognition or executive function in people with dementia living in nursing homes when compared with an attention control activity, notwithstanding dementia type, sex, or cognitive level at baseline.

\section{ACKNOWLEDGMENTS}

We would like to express our sincere gratitude to all who contributed to data collection and implementation of the UMDEX study, as well as, the Social Authorities of the Municipality of Umeå, care staff, and participants.

This work was supported by the Swedish Research Council (grant numbers K2009-69P-21298-01-4, K2009-69X-21299-01-1， K2009-69P-21298-04-4, K2014-99X-22610-01-6); Forte - Swedish Research Council for Health, Working Life and Welfare 
(formerly FAS - Swedish Council for Working Life and Social Research; grant number 2012-0775); the Vårdal Foundation; the Swedish Dementia Association; the Promobilia Foundation; the Swedish Society of Medicine; the Swedish Alzheimer Foundation; the King Gustav V and Queen Victoria's Foundation of Freemasons; the County Council of Västerbotten, the Umeå University Foundation for Medical Research; the Ragnhild and Einar Lundström's Memorial Foundation; and the Erik and Anne-Marie Detlof's Foundation.

Authors' disclosures available online (http://j-alz. com/manuscript-disclosures/17-0014r3).

\section{SUPPLEMENTARY MATERIAL}

The supplementary material is available in the electronic version of this article: http://dx.doi.org/ 10.3233/JAD-170014.

\section{REFERENCES}

[1] World Health Organization (2012) Dementia: A public health priority, World Health organization, Geneva, Switzerland.

[2] American Psychiatric Association (2000) Diagnostic and Statistical Manual of Mental Disorders, Fourth Edition, Text Revision, American Psychiatric Association, Washington, DC.

[3] Allali G, Annweiler C, Blumen HM, Callisaya ML, De Cock AM, Kressig RW, Srikanth V, Steinmetz JP, Verghese J, Beauchet O (2015) Gait phenotype from mild cognitive impairment to moderate dementia: Results from the GOOD initiative. Eur J Neurol 23, 527-541.

[4] Allan LM, Ballard CG, Burn DJ, Kenny RA (2005) Prevalence and severity of gait disorders in Alzheimer's and non-Alzheimer's dementias. J Am Geriatr Soc 53, 16811687.

[5] Morris R, Lord S, Bunce J, Burn D, Rochester L (2016) Gait and cognition: Mapping the global and discrete relationships in ageing and neurodegenerative disease. Neurosci Biobehav Rev 64, 326-345.

[6] Tan CC, Yu JT, Wang HF, Tan MS, Meng XF, Wang C, Jiang T, Zhu XC, Tan L (2014) Efficacy and safety of donepezil, galantamine, rivastigmine, and memantine for the treatment of Alzheimer's disease: A systematic review and meta-analysis. J Alzheimers Dis 41, 615-631.

[7] Birks J, McGuinness B, Craig D (2013) Rivastigmine for vascular cognitive impairment. Cochrane Database Syst Rev, CD004744.

[8] Norton S, Matthews FE, Barnes DE, Yaffe K, Brayne C (2014) Potential for primary prevention of Alzheimer's disease: An analysis of population-based data. Lancet Neurol 13, 788-794.

[9] Erickson KI, Weinstein AM, Lopez OL (2012) Physical activity, brain plasticity, and Alzheimer's disease. Arch Med Res 43, 615-621.

[10] Davenport MH, Hogan DB, Eskes GA, Longman RS, Poulin MJ (2012) Cerebrovascular reserve: The link between fitness and cognitive function? Exerc Sport Sci Rev 40, 153-158.

[11] Sink KM, Espeland MA, Castro CM, Church T, Cohen R, Dodson JA, Guralnik J, Hendrie HC, Jennings J, Katula J, Lopez OL, McDermott MM, Pahor M, Reid KF, Rushing J, Verghese J, Rapp S, Williamson JD; Life Study Investigators (2015) Effect of a 24-month physical activity intervention vs health education on cognitive outcomes in sedentary older adults: The LIFE randomized trial. JAMA 314, 781-790.

[12] Young J, Angevaren M, Rusted J, Tabet N (2015) Aerobic exercise to improve cognitive function in older people without known cognitive impairment. Cochrane Database Syst Rev 4, CD005381.

[13] Forbes D, Forbes SC, Blake CM, Thiessen EJ, Forbes $S$ (2015) Exercise programs for people with dementia. Cochrane Database Syst Rev 4, CD006489.

[14] Toots A, Littbrand H, Lindelöf N, Wiklund R, Holmberg H, Nordström P, Lundin-Olsson L, Gustafson Y, Rosendahl E (2016) Effects of a high-intensity functional exercise program on dependence in activities of daily living and balance in older adults with dementia. $J$ Am Geriatr Soc 64, 55-64.

[15] Bossers WJ, van der Woude LH, Boersma F, Hortobagyi T, Scherder EJ, van Heuvelen MJ (2015) A 9-week aerobic and strength training program improves cognitive and motor function in patients with dementia: A randomized, controlled trial. Am J Geriatr Psychiatry 23, 1106-1116.

[16] Telenius EW, Engedal K, Bergland A (2015) Effect of a high-intensity exercise program on physical function and mental health in nursing home residents with dementia: An assessor blinded randomized controlled trial. PLoS One 10, e0126102.

[17] Arcoverde C, Deslandes A, Moraes H, Almeida C, de Araujo NB, Vasques PE, Silveira H, Laks J (2014) Treadmill training as an augmentation treatment for Alzheimer's disease: A pilot randomized controlled study. Arq Neuropsiquiatr 72, 190-196.

[18] Öhman H, Savikko N, Strandberg TE, Kautiainen H, Raivio MM, Laakkonen ML, Tilvis R, Pitkälä KH (2016) Effects of exercise on cognition: The Finnish Alzheimer disease exercise trial: A randomized, controlled trial. J Am Geriatr Soc 64, 731-738.

[19] Cancela JM, Ayan C, Varela S, Seijo M (2016) Effects of a long-term aerobic exercise intervention on institutionalized patients with dementia. J Sci Med Sport 19, 293-298.

[20] Kemoun G, Thibaud M, Roumagne N, Carette P, Albinet C, Toussaint L, Paccalin M, Dugue B (2010) Effects of a physical training programme on cognitive function and walking efficiency in elderly persons with dementia. Dement Geriatr Cogn Disord 29, 109-114.

[21] Venturelli M, Scarsini R, Schena F (2011) Six-month walking program changes cognitive and ADL performance in patients with Alzheimer. Am J Alzheimers Dis Other Demen 26, 381-388.

[22] Vreugdenhil A, Cannell J, Davies A, Razay G (2012) A community-based exercise programme to improve functional ability in people with Alzheimer's disease: A randomized controlled trial. Scand J Caring Sci 26, 12-19.

[23] McCarney R, Warner J, Iliffe S, van Haselen R, Griffin M, Fisher P (2007) The Hawthorne Effect: A randomised, controlled trial. BMC Med Res Methodol 7, 30.

[24] Simonsick EM, Kasper JD, Phillips CL (1998) Physical disability and social interaction: Factors associated with low social contact and home confinement in disabled older women (The Women's Health and Aging Study). J Gerontol B Psychol Sci Soc Sci 53, S209-S217. 
[25] Kolanowski A, Litaker M (2006) Social interaction, premorbid personality, and agitation in nursing home residents with dementia. Arch Psychiatr Nurs 20, 12-20.

[26] Boström G, Conradsson M, Hörnsten C, Rosendahl E, Lindelöf N, Holmberg H, Nordström P, Gustafson Y, Littbrand $\mathrm{H}$ (2016) Effects of a high-intensity functional exercise program on depressive symptoms among people with dementia in residential care: A randomized controlled trial. Int J Geriatr Psychiatry 31, 868-878.

[27] Toots A, Littbrand H, Holmberg H, Nordström P, LundinOlsson L, Gustafson Y, Rosendahl E (2017) Walking aids moderate exercise effects on gait speed in people with dementia: A randomized controlled trial. J Am Med Dir Assoc 18, 227-233.

[28] Folstein MF, Folstein SE, McHugh PR (1975) "Mini-mental state". A practical method for grading the cognitive state of patients for the clinician. J Psychiatr Res 12, 189-198.

[29] Katz S, Ford AB, Moskowitz RW, Jackson BA, Jaffe MW (1963) Studies of illness in the aged. The index of ADL: A standardized measure of biological and psychosocial function. JAMA 185, 914-919.

[30] Littbrand H, Lindelöf N, Rosendahl E (2014) The HIFE Program: The High-Intensity Functional Exercise Program, 2nd ed., Umeå University, Department of Community Medicine and Rehabilitation, Geriatric Medicine, Umeå. ISBN 978-91-7601-166-9.

[31] Littbrand H, Rosendahl E, Lindelöf N, Lundin-Olsson L, Gustafson Y, Nyberg L (2006) A high-intensity functional weight-bearing exercise program for older people dependent in activities of daily living and living in residential care facilities: Evaluation of the applicability with focus on cognitive function. Phys Ther 86, 489-498.

[32] Delorme TL (1945) Restoration of muscle power by heavyresistance exercises. J Bone Joint Surg 27, 645-667.

[33] Pollock ML, Gaesser GA, Butcher JD, Després J-P, Dishman RK, Franklin BA, Garber CE (1998) American College of Sports Medicine Position Stand. The recommended quantity and quality of exercise for developing and maintaining cardiorespiratory and muscular fitness, and flexibility in healthy adults. Med Sci Sports Exerc 30, 975-991.

[34] Tombaugh TN, McIntyre NJ (1992) The mini-mental state examination: A comprehensive review. J Am Geriatr Soc 40, 922-935.

[35] Rosen WG, Mohs RC, Davis KL (1984) A new rating scale for Alzheimer's disease. Am J Psychiatry 141, 1356-1364.

[36] Cano SJ, Posner HB, Moline ML, Hurt SW, Swartz J, Hsu T, Hobart JC (2010) The ADAS-cog in Alzheimer's disease clinical trials: Psychometric evaluation of the sum and its parts. J Neurol Neurosurg Psychiatry 81, 1363-1368.

[37] Morris JC, Heyman A, Mohs RC, Hughes JP, van Belle G, Fillenbaum G, Mellits ED, Clark C (1989) The Consortium to Establish a Registry for Alzheimer's Disease
(CERAD). Part I. Clinical and neuropsychological assessment of Alzheimer's disease. Neurology 39, 1159-1165.

[38] Guigoz Y, Vellas B, Garry PJ (1994) Mini Nutritional Assessment: A practical assessment tool for grading the nutritional state of elderly patients. Facts Res Gerontol S2 15-59.

[39] Ware JE Jr, Sherbourne CD (1992) The MOS 36-item shortform health survey (SF-36). I. Conceptual framework and item selection. Med Care 30, 473-483.

[40] Sheikh JI, Yesavage JA (1986) Geriatric Assessment Scale (GDS): Recent evidence and development of a shorter version. Clin Gerontol 5, 165-172.

[41] Chodzko-Zajko WJ, Proctor DN, Fiatarone Singh MA, Minson CT, Nigg CR, Salem GJ, Skinner JS (2009) American College of Sports Medicine position stand. Exercise and physical activity for older adults. Med Sci Sports Exerc 41, 1510-1530.

[42] de Souto Barreto P, Morley JE, Chodzko-Zajko W, H Pitkala $\mathrm{K}$, Weening-Djiksterhuis E, Rodriguez-Manas L, Barbagallo M, Rosendahl E, Sinclair A, Landi F, Izquierdo M, Vellas B, Rolland Y, International Association of Gerontology and Geriatrics - Global Aging Research Network (IAGG-GARN), the IERCS (2016) Recommendations on physical activity and exercise for older adults living in longterm care facilities: A taskforce report. J Am Med Dir Assoc 17, 381-392.

[43] Hoffmann K, Sobol NA, Frederiksen KS, Beyer N, Vogel A, Vestergaard K, Braendgaard H, Gottrup H, Lolk A, Wermuth L, Jacobsen S, Laugesen LP, Gergelyffy RG, Hogh P, Bjerregaard E, Andersen BB, Siersma V, Johannsen P, Cotman CW, Waldemar G, Hasselbalch SG (2015) Moderate-to-high intensity physical exercise in patients with Alzheimer's disease: A randomized controlled trial. J Alzheimers Dis 50, 443-453.

[44] Sobol NA, Hoffmann K, Frederiksen KS, Vogel A, Vestergaard K, Braendgaard H, Gottrup H, Lolk A, Wermuth L, Jakobsen S, Laugesen L, Gergelyffy R, Hogh P, Bjerregaard E, Siersma V, Andersen BB, Johannsen P, Waldemar G, Hasselbalch SG, Beyer N (2016) Effect of aerobic exercise on physical performance in patients with Alzheimer's disease. Alzheimers Dement 12, 1207-1215.

[45] Erickson KI, Voss MW, Prakash RS, Basak C, Szabo A, Chaddock L, Kim JS, Heo S, Alves H, White SM, Wojcicki TR, Mailey E, Vieira VJ, Martin SA, Pence BD, Woods JA, McAuley E, Kramer AF (2011) Exercise training increases size of hippocampus and improves memory. Proc Natl Acad Sci U S A 108, 3017-3022.

[46] Woods B, Aguirre E, Spector AE, Orrell M (2012) Cognitive stimulation to improve cognitive functioning in people with dementia. Cochrane Database Syst Rev (2), CD005562. 